\title{
EPIDEMIOLOGY AND DIAGNOSIS OF CYSTIC ECHINOCOCCOSIS IN INTERMEDIATES HOST IN THE PROVINCE OF DJELFA, ALGERIA
}

\author{
Hamrat Khadidja $^{1,2}$, Yahia Achour ${ }^{3 *}$, Saidani Khelaf ${ }^{3}$ \\ ${ }^{1}$ Directorate of Agricultural Services, Veterinary inspection, Djelfa, Algeria ; \\ ${ }^{2}$ Parasitology department, Faculty of Veterinary Medicine, University of Agricultural Sciences and Veterinary \\ Medicine. Cluj-Napoca, Romania ; \\ ${ }^{3 *}$ University of Blida 1, Veterinary Sciences Institute, Laboratory of Biotechnology related to Animal Reproduction, \\ Blida, Algeria ;
}

*Corresponding Author Yahia Achour, e-mail : achourveto@yahoo.fr;

Received June 2020; Accepted July 2020; Published August 2020;

DOI: https://doi.org/10.31407/ijees10.316

\begin{abstract}
The aims of this study was to determine the prevalence of Cystic Echinococcosis (CE) and the comparison between the results of the post mortem and serological diagnosis of this infestation in the intermediates host in the province of Djelfa (ALGERIA). The study was carried out on a total of 192 animals composed of 40 cattle, 96 sheep and 56 goats. Prevalences of 30\%, $21.8 \%$ and $14.3 \%$ were recorded by the post mortem examination, against prevalences of $35 \%, 36.4 \%, 19.6 \%$ recorded by the ELISA test in cattle, sheep and goats respectively. High significant dependence between the two methods of diagnostic (necropsy examination and ELISA test) was found concerning the prevalence of hydatidosis $(\mathrm{P}<0.05)$. A concordance of the results (convergence) between the two diagnostic methods was observed in $81 \%$ of the examined cases. However, a discord in the results (divergence) between the two methods was found in 19\% of the examined cases. In sheep and goats, the prevalence observed in female was higher than male. However in cattle the prevalence was higher in male (31.2\%) compared to female (25\%). In all screened animals there was not significant difference between the two sexes $(\mathrm{P}>0.05)$. A higher prevalence $73 \%$ was recorded in adult infested animals (cattle, sheep and goats) as compared to younger animals $27 \%$. The lungs were the mostly affected organ with the cystic echinococcosis, with a prevalence of $62.5 \%, 58.3 \%$ and $57.1 \%$ respectively in goats, cattle and sheep. These results indicate the importance of cystic echinococcosis in slaughtered domestic animals in the province of Djelfa and an ELISA test could be used for immunodiagnosis of this disease for epidemiological studies and surveillance schemes.
\end{abstract}

Keywords: Djelfa, Echinococcus granulosus, ELISA, Necropsy, Prevalence. 